\title{
Laccase Activity from Pleurotus ostreatus and Flammulina velutipes Strains Grown on Agro- and Forestry Residues by Solid-state Fermentation
}

\author{
Qi An, ${ }^{\text {a,b }}$ Ze-Yang Liu, ${ }^{\text {a }}$ Chun-Rui Wang, ${ }^{\text {a Jing Yang, }}{ }^{\text {a Si-Yu Chen, }}{ }^{\text {a Xi Chen, }}{ }^{\text {a }}$ \\ Yi-Jie Zhang, ${ }^{a}$ Lu-Sen Bian, ${ }^{\mathrm{d}}$ and Mei-Ling Han ${ }^{\mathrm{a}, \mathrm{b}, \mathrm{c}, *}$
}

\begin{abstract}
Laccase activity from Pleurotus ostreatus and Flammulina velutipes strains was investigated with various agro- and forestry residues by solidstate fermentation. Different species or strains belonging to the same species had the unique capacity of secreting laccase on solid-state fermentation with various agro- and forestry residues. Overall, the capacity of secreting laccase for $P$. ostreatus strains was superior to $F$. velutipes strains due to the value of maximum activity on various agro- and forestry residues, except on the stalk of straw. Compared with Populus beijingensis, corncob, and stalk of straw, the presence of cottonseed hull was helpful to improve laccase activity for $P$. ostreatus strains because the maximum laccase activity from cottonseed hull was higher than that from the other three agro- and forestry residues. The presence of stalk of straw was more helpful to improve laccase activity for $F$. velutipes strains because of the maximum laccase activity from stalk of straw was higher that from Populus beijingensis, corncob, and cottonseed hull. These results indicated the importance of selecting suitable agro- and forestry residues for fungi producing laccase. These findings contributed to the selection of suitable strains to obtain an integrated application of low-cost laccase in the factory.
\end{abstract}

Keywords: Pleurotus ostreatus; Flammulina velutipes; Laccase activity; Agro- and forestry residues; Solid-state fermentation

Contact information: a: College of Life Science, Langfang Normal University, Langfang 065000, Hebei, China; b: Technical Innovation Center for Utilization of Edible and Medicinal Fungi in Hebei Province, Langfang 065000, Hebei, China; c: Edible and Medicinal Fungi Research and Development Center of Universities/Colleges in Hebei Province, Langfang 065000, Hebei, China; d: Experimental Centre of Forestry in North China, Chinese Academy of Forestry, Beijing 102300, China;

* Corresponding author: meilinghan309@163.com

\section{INTRODUCTION}

The development of agriculture and forestry has brought great economic benefits and contributed to environmental protection because of their ability in absorbing carbon dioxide and releasing oxygen. The role agriculture and forestry plays in soil and water conservation is also extremely important. However, the rapid development of agriculture and forestry also brings some environmental problems, mainly including the residues agroand forestry harvesting practices. What is more serious is that these agro- and forestry residues will cause more air pollution if they were disposed of via burning. However, these agro- and forestry residues belonging to biomass resources have broad application value in various aspects including green energy fuels and industrial chemical products (Gaikwad and Meshram 2019). Agro- and forestry residues, e.g., sugarcane bagasse, grasses, corncob, 
cottonseed hull, bamboos, etc., are composed of lignin, cellulose, and hemicellulose (Pinheiro et al. 2020). The production of enzymes via agro- and forestry residues has attracted widespread attention, especially laccase, due to the wide existence and low price of agro- and forestry residues (Lizardi-Jimenez et al. 2019; Palazzolo et al. 2019; Srinivasan et al. 2019; Thamvithayakorn et al. 2019; Agrawal and Verma 2020; AtilanoCamino et al. 2020; Pinheiro et al. 2020; Xu et al. 2020).

Laccase (EC 1.10.3.2), one of most important ligninolytic enzymes, alone or together with other ligninolytic enzymes, including lignin peroxidase (Lip) and manganese peroxidase (Mnp), belongs to a family of copper oxidases and is distributed in higher plants, cyanobacteria, bacteria, insects, and fungi (Yang et al. 2017; Srinivasan et al. 2019). Laccase has the ability of catalyzing a wide range of reactions, including organic and inorganic substrates (Sharma et al. 2007; Jaya Mary et al. 2018). High catalytic capacity and wide substrate adaptation of laccase greatly improves the wide application of enzyme in various fields, including bioremediation, biodegradation, biosensors, medicine, nanoscience, pulp and paper industry, baking industry, and beverage and beer industry (Bertrand et al. 2017; Kudanga et al. 2017; Mate and Alcalde 2017; Agrawal et al. 2018; Su et al. 2018; Yashas et al. 2018; Deska and Konczak 2019; Garlapati et al. 2019; Singh and Arya 2019; Wang et al. 2019; Zerva et al. 2020; Liu et al. 2020). The wide application of laccase to the above-mentioned biotechnological process requires large amounts of laccase with low production cost (Couto and Toca-Herrera 2007; An et al. 2018). Therefore, reducing the production costs of laccase by optimising the fermentation condition and selecting suitable strains to obtain high laccase production are the key research questions for industrial applications (Elisashvili et al. 2008; Mate and Alcalde 2017; Rodrigues et al. 2019; An et al. 2020a,b). At present, fungal laccase and bacterial laccase have been widely studied, especially fungal laccase. Many fungi have ability of secreting laccase, mainly basidiomycetes. White-rot fungi, belonging to basidiomycetes, are recognized as excellent laccases producers, and almost all species of white-rot fungi can secrete laccase to varying degrees (Couto and Toca-Herrera 2007; An et al. 2016a,b; Agrawal et al. 2018). Among the white-rot fungi, laccase production from the genus Ganoderma, Trametes, Lentinus, and Pleurotus are the most widely studied (Elissetche et al. 2007; Guo et al. 2017; Gupta and Jana 2018, 2019; Palazzolo et al. 2019; Sadeghian-Abadi et al. 2019; Atilano-Camino et al. 2020; Han et al. 2020).

The activity of laccase secreted by fungi is affected by many factors. Additionally, it mainly includes the following categories: 1) the concentration, proportion, and type of carbon or nitrogen sources, such as glucose, peptone, and lignocellulosic biomass (Songulashvili et al. 2008; An et al. 2015; Han et al. 2017; Palazzolo et al. 2019; Thamvithayakorn et al. 2019; Agrawal and Verma 2020; Atilano-Camino et al. 2020; Pinheiro et al. 2020); 2) various kinds or concentration of metal ions, e.g., $\mathrm{Ca}^{2+}, \mathrm{Cu}^{2+}, \mathrm{Cd}^{2+}$, $\mathrm{Ag}^{2+}, \mathrm{Fe}^{2+}, \mathrm{Hg}^{2+}$, and $\mathrm{Mn}^{2+}$ (Wang et al. 2011; Pezzella et al. 2013; Divya et al. 2015; Suetomi et al. 2015; Zhuo et al. 2017; Xu et al. 2018; An et al. 2020a); 3) fungal secondary metabolites, such as veratrol and ferulic acid (Galhaup et al. 2002; Janusz et al. 2015); 4) temperature and pH (Diaz et al. 2013; Hu et al. 2014); 5) fermentation method, including submerged fermentation, solid-state fermentation and unconventional method (solid-state fermentation followed by liquid fermentation) (An et al. 2016b; Schalchli et al. 2017; Wasak et al. 2018; Gupta and Jana 2019; Wang et al. 2019); 6) different species or strains (Elisashvili and Kachlishvili 2009; An et al. 2016a, 2018; Zhang et al. 2020; Han et al. 2021).

Previous study showed that solid-state fermentation is better than submerged 
fermentation in that the enzymes are not diluted (Oostra et al. 2000). Moreover, solid-state fermentation is closer to the real living environment of fungi in nature. Lignocellulosic biomass is often used as the material for fungal growth by solid-state fermentation. Previous studies indicated that a difference among different fungal species or different strains belonging to the same species for biosynthetic potential was significant (Janusz et al. 2015; Vrsanska et al. 2016; Han et al. 2020). However, it is necessary to select the substrates suitable for each fungus to grow and secrete laccase because different fungi prefer different substrates. Meanwhile, laccase activity from Pleurotus ostreatus CCEF 89 or CCEF 99 on corncob, poplar wood and cottonseed hull had been detected in previous studies (Han et al. 2017, 2018). However, more strains and more kinds of agro- and forestry residues were necessary for obtaining suitable strain and fermentation condition. Based on this, in this study, laccase activity of strains belonging to Pleurotus ostreatus and Flammulina velutipes were investigated with various agro- and forestry residues on solidstate fermentation. The enzyme production capacity of strains from Pleurotus ostreatus and Flammulina velutipes was also compared. The results will provide a basis for the selection of suitable agro- and forestry residues for different strains to obtain low-cost laccase in the factory.

\section{EXPERIMENTAL}

\section{Materials}

Microorganisms

Three Pleurotus ostreatus strains CCMSSC 00322, CCMSSC 00406, and CCMSSC 00336 and three Flammulina velutipes strains CCMSSC 00114, CCMSSC 00118, and CCMSSC 05317 were used in this study. All strains were kindly provided by Institute of Microbiology, Beijing Forestry University (Beijing, China) and preserved on Malt Extract Agar (MEA) medium in the College of Life Science, Langfang Normal University (Langfang, China).

\section{Collection and treatment of agro- and forestry residues}

Populus beijingensis was collected from Langfang (China), while corncob, stalk of straw, and cottonseed hull were collected from farmland in Chengde (China). All collected agro- and forestry residues were air-dried and milled to a particle size of between 20- and 60-mesh.

\section{Methods}

Microbial culture and inoculum preparation

All microorganisms were reactivated on MEA medium with a stable culture temperature of $26^{\circ} \mathrm{C}$. After 7 days of culture, round pieces with a diameter of $5 \mathrm{~mm}$ were punched out with a hole punch, forming the inoculants for subsequent using. Then, to prepare the seed fluid, 5 inoculants were cultured in 250-mL Erlenmeyer flasks with 100 $\mathrm{mL}$ of MEA liquid medium (without agar) at $26^{\circ} \mathrm{C}$ in a shaking condition with a speed of $150 \mathrm{rpm}$. Seven days later, well grown seed fluid was homogenized by a laboratory blender for 2 min with a stable speed of $5000 \mathrm{rpm}$, and the well-stirred suspension was taken for the inoculum. 
Laccase production from $P$. ostreatus and $F$. velutipes strains

A total of $3 \mathrm{~g}$ of dry Populus beijingensis was added to a 250-mL Erlenmeyer flask and moistened with $12 \mathrm{~mL}$ deionized water. All flasks were sterilized, cooled down to room temperature, and inoculated with $3 \mathrm{~mL}$ inoculum under sterile conditions. Other agro- and forestry residues, corncob, stalk of straw, and cottonseed hull, were followed the steps aforementioned. All flasks were incubated at $26{ }^{\circ} \mathrm{C}$ and underwent the step of solid-state fermentation. Every $24 \mathrm{~h}$, the flasks were taken out and added into $100 \mathrm{~mL}$ acetate-sodium acetate buffer ( $50 \mathrm{mM}, \mathrm{pH} 5.5)$ to perform the extraction process. Extraction process was carried out in a shaker for $4 \mathrm{~h}\left(10^{\circ} \mathrm{C}, 120 \mathrm{rpm}\right)$ according to Han et al. (2020b). Then, fermentation liquor was filtered through Whatman No. 1 filter paper after removing the agro- and forestry residues. The obtained liquid was centrifuged for $20 \mathrm{~min}\left(4^{\circ} \mathrm{C}, 12000\right.$ $\mathrm{rpm})$. The supernatant after centrifugation was used for measurement of laccase activity.

\section{Determination of Laccase activity}

Laccase activity of $P$. ostreatus and $F$. velutipes strains was determined by the oxidation of 2,2'-azinobis-[3-ethyltiazoline-6-sulfonate] (ABTS) $(1 \mathrm{mM})$, as described in a previous study (Han et al. 2020b). One activity unit was defined as the amount of laccase forming $1 \mu \mathrm{mol}$ of $\mathrm{ABTS}^{+}$per minute $\left(\varepsilon_{420} \mathrm{~nm}=3.6 \times 10^{4} \mathrm{M}^{-1} \mathrm{~cm}^{-1}\right)$ in the acetate-sodium acetate buffer $(50 \mathrm{mM}, \mathrm{pH} 4.2)$ monitored by measuring the optical density (OD) at 420 nm using a Unico UV-4802 spectrophotometer (Unico Instrument Co., Ltd., Shanghai, China). The assay mixture contained $100 \mu \mathrm{L}$ of supernatant prepared and $1 \mathrm{mM}$ ABTS in $50 \mathrm{mM}$ acetate-sodium acetate buffer ( $\mathrm{pH}$ 4.2). The specify duration of the reaction was 5 min with the model of kinetic measurement. The blanks were comprised of ABTS, acetatesodium acetate buffer, and inactive supernatant enzyme solution.

\section{Date analysis}

Two-way analysis of variance was used to examine the effects of agro- and forestry residues and strains on laccase activity and performed by the method of Han et al. (2020b). The software used to complete two-way analysis of variance was SPSS software version 22.0 (PROC GLM, Armonk, NY, USA). All data figures were prepared using Origin 2016 (OriginLab Corporation, Northampton, MA, USA).

\section{RESULTS AND DISCUSSION}

\section{Results of Statistical analysis}

The effect of the agro- and forestry residues on laccase activity of different strains belonging to Pleurotus ostreatus and Flammulina velutipes was significant $(\mathrm{P}<0.001)$ during the 10 days of solid-state fermentation. The effect of the strains belonging to $P$. ostreatus and $F$. velutipes on laccase activity was significant $(\mathrm{P}<0.001)$ during the 10 days of solid-state fermentation. Meanwhile, the interactions of strains and agro- and forestry residues on laccase activity were also significant $(\mathrm{P}<0.001)$ at 10 days on solid-state fermentation (Table 1).

\section{Laccase Activity of Strains Grown on Different Agro- and Forestry Residues}

Agro- and forestry residues were considered as low-cost materials to produce various valuable chemical products including bioethanol and enzymes. Previous studies 
indicated that lignocellulosic materials, belonging to a type of complex carbon and nitrogen sources, could be affected the laccase production secreted by fungi (Pinar et al. 2017; Leite et al. 2019; An et al. 2020b; Han et al. 2020; Rajavat et al. 2020). Widely used kinds of lignocellulosic materials were wood chips, olive pomace, wheat bran, bamboo, and coffee shells (Gaikwad and Meshram 2019; Leite et al. 2019; Xu et al. 2020).

Table 1. Effects of Strains, Agro- and Forestry Residues, and Strains $\times$ Agro- and Forestry Residues Interactions on Laccase Activities of Different Strains (Twoway ANOVA)

\begin{tabular}{|c|c|c|c|}
\hline $\begin{array}{l}\text { Incubation Period } \\
\text { (d) }\end{array}$ & Strains & $\begin{array}{l}\text { Agro- and Forestry } \\
\text { Residues }\end{array}$ & $\begin{array}{c}\text { Strains } \times \text { Agro- and Forestry } \\
\text { Residues }\end{array}$ \\
\hline 1 & $940.907^{\star \star \star}$ & $1194.372^{\star \star \star}$ & $381.677^{\star \star \star}$ \\
\hline 2 & $4853.474^{\star \star \star}$ & $11864.856^{\star * \star}$ & $2614.743^{\star * *}$ \\
\hline 3 & $915.119^{* \star \star}$ & $2465.461^{* * *}$ & $470.000^{\star \star \star}$ \\
\hline 4 & $1305.317^{\star \star \star}$ & $3255.921^{* * *}$ & $742.631^{* * *}$ \\
\hline 5 & $2034.876^{\star * *}$ & $4814.965^{\star * *}$ & $1087.556^{\star * *}$ \\
\hline 6 & $2642.866^{\star \star \star}$ & $3173.666^{\star \star \star}$ & $1175.300^{\star \star \star}$ \\
\hline 7 & $5661.829^{\star * *}$ & $1641.142^{\star * *}$ & $678.269^{\star \star \star}$ \\
\hline 8 & $2114.103^{\star * *}$ & $710.668^{* * *}$ & $254.109^{\star \star \star}$ \\
\hline 9 & $2991.470^{\star \star *}$ & $400.593^{* * *}$ & $494.888^{* \star \star}$ \\
\hline 10 & $1787.983^{\star \star \star}$ & $225.465^{\star \star \star}$ & $298.289^{\star \star \star}$ \\
\hline
\end{tabular}

The planting area of corn, cotton, Populus beijingensis, and Oryza sativa is large, so there are large amounts of corresponding residues. Moreover, P. beijingensis, O. sativa, corn, and cotton were also used for the growing of Pleurotus ostreatus and Flammulina velutipes to obtain a fruit body, which was a process of secreting lignocellulolytic enzymes (Han et al. 2017, 2020; An et al. 2020b). Thus, the investigation on the laccase activity from $P$. ostreatus and $F$. velutipes strains on different agro- and forestry residues was necessary to select suitable biomass for obtaining the low-cost laccase. A previous study had selected the actinobacteria strains to produce lignocellulolytic enzymes with olive pomace as substrate (Lamia et al. 2017). Therefore, this study investigated the laccase activity from $P$. ostreatus and $F$. velutipes strains on Populus beijingensis, stalk of straw, corncob, and cottonseed hull via solid-state fermentation.

Minimum laccase activity from $P$. ostreatus strain CCMSSC 00322 grown on stalk of straw, P. beijingensis, corncob, and cottonseed hull was $2.35 \pm 0.11,2.59 \pm 0.19,9.26$ \pm 0.19 , and $28.21 \pm 1.55 \mathrm{U} / \mathrm{L}$, respectively, and the time of minimum laccase activity all occurred on the $1^{\text {st }}$ day (Figs. 1, 2, 3, and 4, respectively). Thus, minimum laccase activity from strain CCMSSC 00322 on cottonseed hull was nearly 12.00-fold, 10.89-fold, and 3.05-fold higher than that on stalk of straw, P. beijingensis, and corncob, respectively. Therefore, the presence of cottonseed hull was advantageous for $P$. ostreatus strain CCMSSC 00322 to rapidly secrete laccase. Maximum laccase activity from $P$. ostreatus strain CCMSSC 00322 grown on stalk of straw, P. beijingensis, corncob, and cottonseed hull was $312.04 \pm 5.52,303.52 \pm 5.41,321.98 \pm 6.55$, and 594.58 $\pm 4.15 \mathrm{U} / \mathrm{L}$, respectively, and the corresponding occurrence time was on the $7^{\text {th }}$ day, $7^{\text {th }}$ day, $7^{\text {th }}$ day, and $6^{\text {th }}$ day (Table 2). Clearly, maximum laccase activity secreted by strain CCMSSC 00322 on stalk 
of straw, $P$. beijingensis, and corncob maintained an equal level, and was lower than that on cottonseed hull. Previous study indicated that cottonseed hull was helpful for $P$. ostreatus strains to obtain higher laccase production compared with corncob or poplar wood (Han et al. 2017, 2018, 2020), and the advantages of cottonseed hull in improving laccase activity emerged in this study were similar to previous studies. At the end of fermentation (on $10^{\text {th }}$ day), laccase activity from strain CCMSSC 00322 on stalk of straw, $P$. beijingensis, corncob, and cottonseed hull was $23.89 \pm 1.79,103.89 \pm 4.51,129.07 \pm$ 1.65 , and $177.47 \pm 11.88 \mathrm{U} / \mathrm{L}$, respectively (Figs. 1 through 4 ). To some extent, $P$. beijingensis, corncob, and cottonseed hull were all helpful for strain CCMSSC 00322 to secrete stable laccase during whole process of fermentation (Figs. 1, 2, and 4).

Minimum laccase activity from $P$. ostreatus strain CCMSSC 00406 on stalk of straw, $P$. beijingensis, corncob, and cottonseed hull was $2.16 \pm 0.11 \mathrm{U} / \mathrm{L}$ (on $1^{\text {st }}$ day), 1.05 $\pm 0.11 \mathrm{U} / \mathrm{L}$ (on $1^{\text {st }}$ day), $2.90 \pm 0.28 \mathrm{U} / \mathrm{L}$ (on $1^{\text {st }}$ day), and $4.07 \pm 0.32 \mathrm{U} / \mathrm{L}$ (on $1^{\text {st }}$ day), respectively (Figs. 1, 2, 3 and 4). Maximum laccase activity for $P$. ostreatus strain CCMSSC 00406 from cottonseed hull was $417.72 \pm 17.99 \mathrm{U} / \mathrm{L}$ on $5^{\text {th }}$ day, which was higher than that from stalk of straw $\left(253.95 \pm 5.86 \mathrm{U} / \mathrm{L}, 8^{\text {th }}\right.$ day), Populus beijingensis $\left(265.86 \pm 13.28 \mathrm{U} / \mathrm{L}, 7^{\text {th }}\right.$ day $)$, and corncob $\left(148.15 \pm 7.38 \mathrm{U} / \mathrm{L}, 6^{\text {th }}\right.$ day $)$, by $1.64-f o l d, 1.57-$ fold, and 2.82-fold, respectively (Table 2). Laccase activity from strain CCMSSC 00406 at 10th day on stalk of straw, $P$. beijingensis, corncob, and cottonseed hull was $32.35 \pm$ $2.39,67.84 \pm 1.83,16.23 \pm 1.50$, and $49.20 \pm 3.18 \mathrm{U} / \mathrm{L}$, respectively. The maximum activity of laccase on $P$. beijingensis was lower than that on cottonseed hull, but laccase activity on $P$. beijingensis was higher than that on cottonseed hull at $10^{\text {th }}$ day (Figs. 1 and 4).

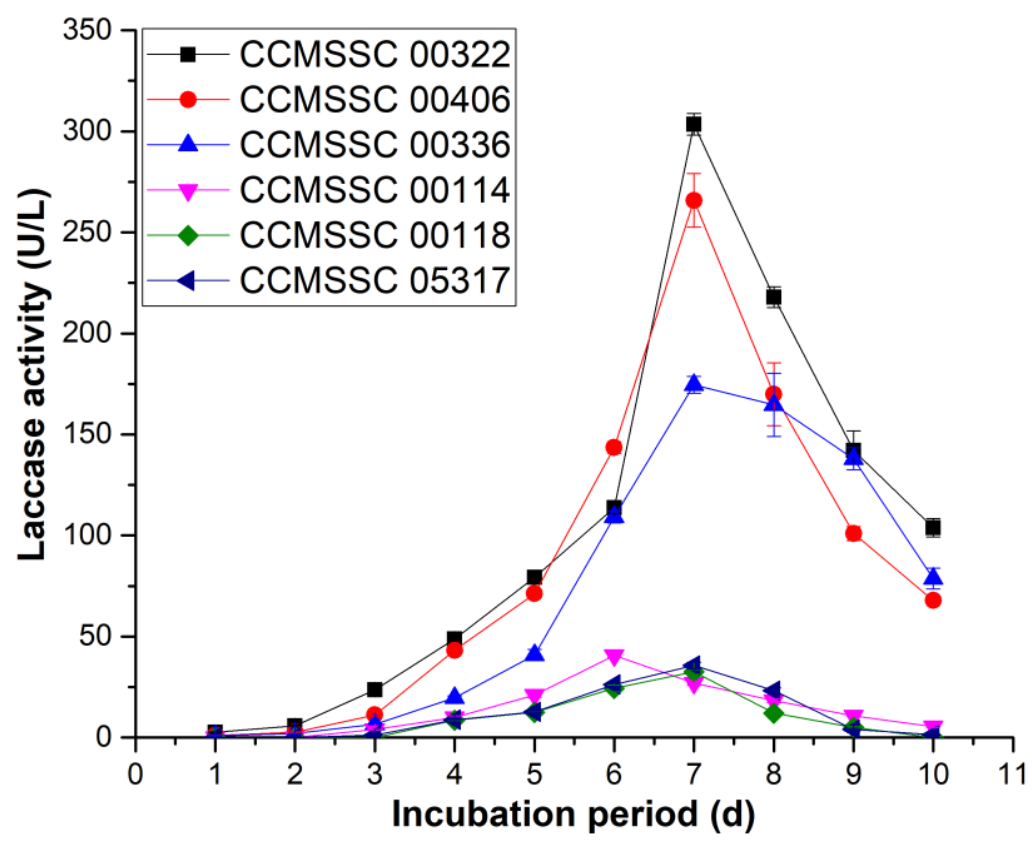

Fig. 1. Laccase activity from $P$. ostreatus strains CCMSSC 00322, CCMSSC 00406, and CCMSSC 00336 and F. velutipes strains CCMSSC 00114, CCMSSC 00118, and CCMSSC 05317 on $P$. beijingensis. Mean value was calculated using three independent parallel values. 


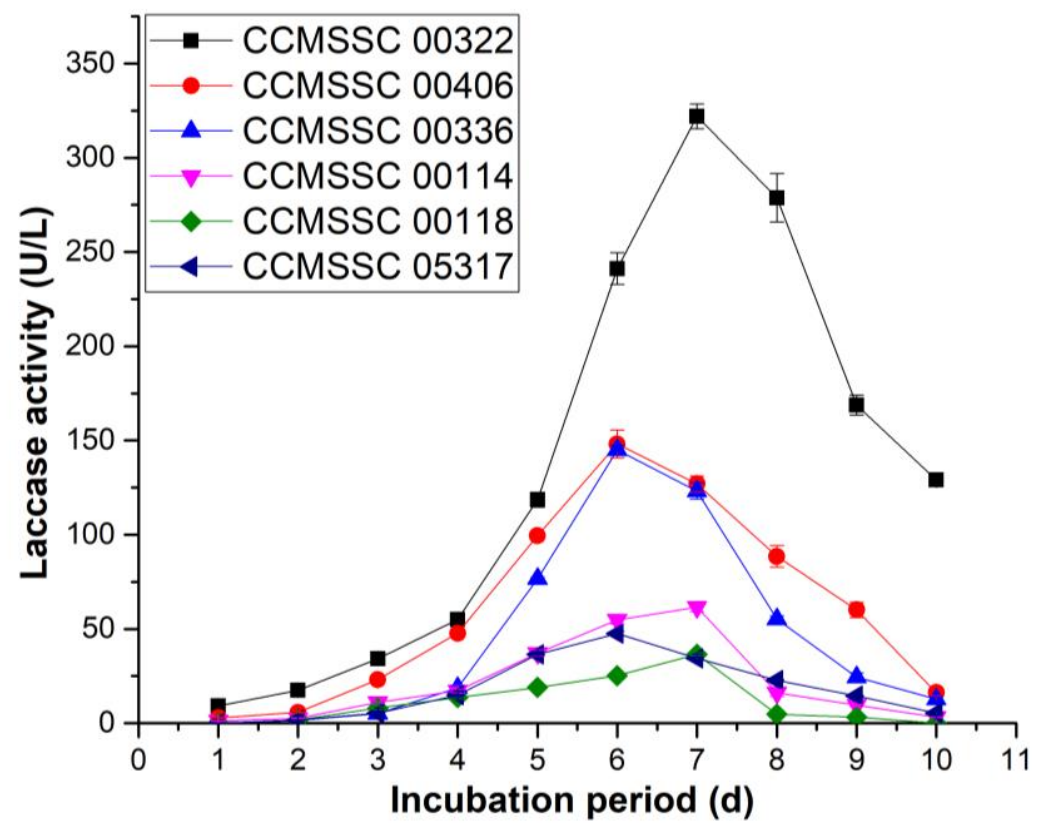

Fig. 2. Laccase activity from $P$. ostreatus strains CCMSSC 00322, CCMSSC 00406, and CCMSSC 00336 and F. velutipes strains CCMSSC 00114, CCMSSC 00118, and CCMSSC 05317 on corncob. Mean value was calculated using three independent parallel values.

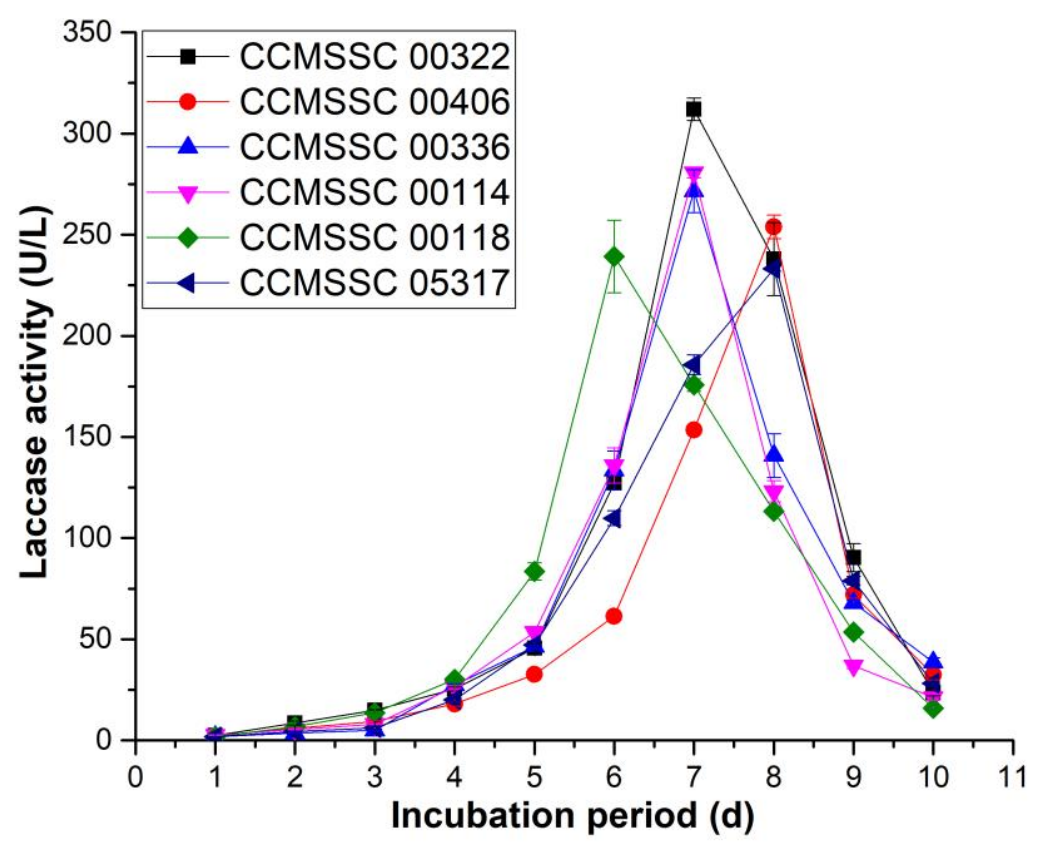

Fig. 3. Laccase activity from $P$. ostreatus strains CCMSSC 00322, CCMSSC 00406, and CCMSSC 00336 and F. velutipes strains CCMSSC 00114, CCMSSC 00118, and CCMSSC 05317 on stalk of straw. Mean value was calculated using three independent parallel values. 


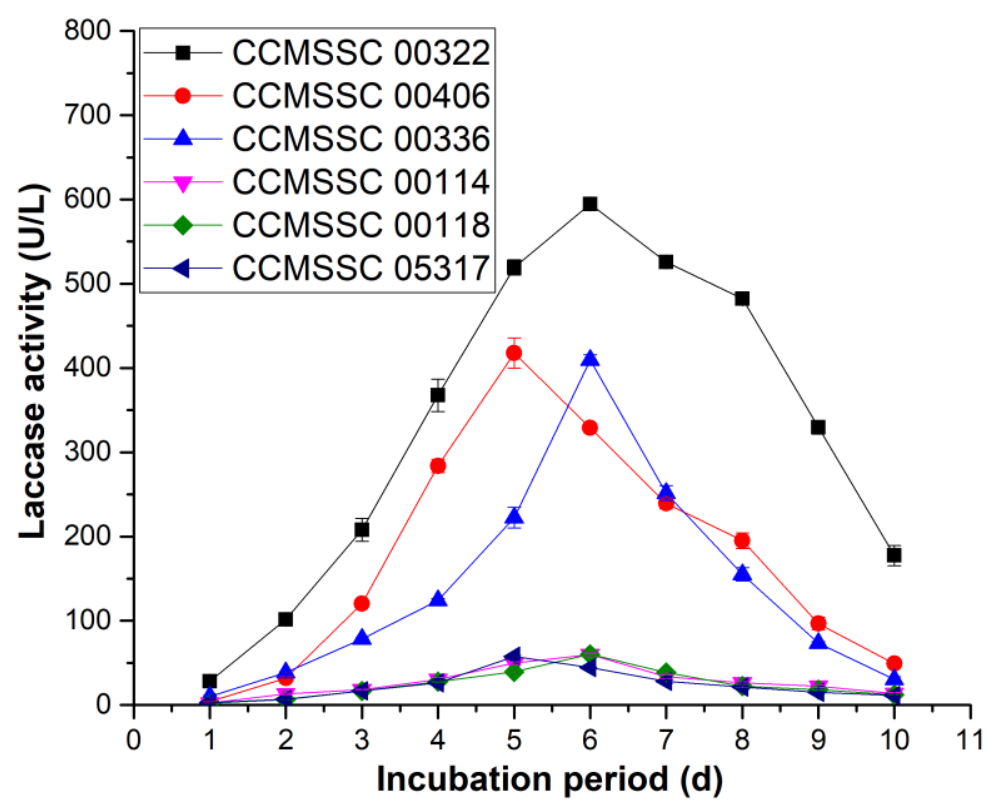

Fig. 4. Laccase activity from $P$. ostreatus strains CCMSSC 00322, CCMSSC 00406, and CCMSSC 00336 and F. velutipes strains CCMSSC 00114, CCMSSC 00118, and CCMSSC 05317 on cottonseed hull. Mean value was calculated using three independent parallel values.

Minimum laccase activity for P. ostreatus strain CCMSSC 00336 from agro- and forestry residues with stalk of straw, $P$. beijingensis, corncob, and cottonseed hull was 1.91 $\pm 0.11,0.86 \pm 0.11,0 \pm 0$, and 10.19 $\pm 1.13 \mathrm{U} / \mathrm{L}$, respectively, and all appeared on $1^{\text {st }}$ day. Minimum laccase activity for strain CCMSSC 00336 on cottonseed hull was nearly 5.34fold and 11.85-fold higher than that on stalk of straw and P. beijingensis, respectively, while no laccase activity was detected on corncob at the same time. The maximum laccase activity from strain CCMSSC 00336 on cottonseed hull $\left(409.44 \pm 6.49 \mathrm{U} / \mathrm{L}, 6^{\text {th }}\right.$ day) was higher than that on stalk of straw $\left(271.54 \pm 10.58 \mathrm{U} / \mathrm{L}, 7^{\text {th }}\right.$ day), Populus beijingensis $\left(174.51 \pm 4.18 \mathrm{U} / \mathrm{L}, 7^{\text {th }}\right.$ day $)$, and corncob $\left(145.00 \pm 2.59 \mathrm{U} / \mathrm{L}, 6^{\text {th }}\right.$ day $)$, by 1.51 -fold, $2.35-$ fold, and 2.82-fold, respectively (Table 2). Thus, cottonseed hull and stalk of straw improved laccase activity for strain CCMSSC 00336 . At the $10^{\text {th }}$ day, laccase activity from strain CCMSSC 00336 grown on stalk of straw, P. beijingensis, corncob, and cottonseed hull was $38.64 \pm 2.29,78.64 \pm 5.18,12.84 \pm 1.12$, and $30.62 \pm 2.93$ U/L (Figs. 1 through 4 , respectively).

Minimum laccase activity from $F$. velutipes strain CCMSSC 00114 on stalk of straw, $P$. beijingensis, corncob, and cottonseed hull was $2.59 \pm 0.19 \mathrm{U} / \mathrm{L}, 0 \pm 0 \mathrm{U} / \mathrm{L}, 1.23$ $\pm 0.11 \mathrm{U} / \mathrm{L}$, and $2.47 \pm 0.11 \mathrm{U} / \mathrm{L}$ (Figs. 1, 2, 3, and 4, respectively). Maximum laccase activity from strain CCMSSC 00114 on stalk of straw was $280.80 \pm 2.75 \mathrm{U} / \mathrm{L}$, higher than that on P. beijingensis (40.62 $\pm 0.95 \mathrm{U} / \mathrm{L})$, corncob $(61.67 \pm 2.49 \mathrm{U} / \mathrm{L})$, and cottonseed hull (59.88 $\pm 1.95 \mathrm{U} / \mathrm{L})$, by nearly 6.91-fold, 4.55-fold, and 4.69-fold (Table 2), respectively.

Additionally, laccase activity on stalk of straw was higher that on $P$. beijingensis, corncob, and cottonseed hull, by nearly 3.88-fold, 6.76-fold, and 1.54-fold, respectively. Clearly, stalk of straw contributed to $F$. velutipes strain CCMSSC 00114 to secrete laccase rapidly and improve laccase activity. At the beginning of the fermentation ( $1^{\text {st }}$ day), laccase activity from $F$. velutipes strain CCMSSC 00118 on stalk of straw and cottonseed hull was 
$1.91 \pm 0.11$ and $2.16 \pm 0.11 \mathrm{U} / \mathrm{L}$, respectively, while no laccase activity was detected on $P$. beijingensis and corncob (Figs. 1, 2, 3, and 4, respectively). Maximum laccase activity from strain CCMSSC 00118 on stalk of straw $\left(239.26 \pm 17.89 \mathrm{U} / \mathrm{L}, 6^{\text {th }}\right.$ day) was higher than that on $P$. beijingensis $\left(32.47 \pm 1.12 \mathrm{U} / \mathrm{L}, 7^{\text {th }}\right.$ day $)$, corncob $\left(36.60 \pm 0.70 \mathrm{U} / \mathrm{L}, 7^{\text {th }}\right.$ day), and cottonseed hull $\left(60.19 \pm 2.80 \mathrm{U} / \mathrm{L}, 6^{\text {th }}\right.$ day), by 7.37-fold, 6.54-fold, and 3.98fold, respectively (Table 2).

At the end stage of fermentation $\left(10^{\text {th }}\right.$ day $)$, similarly to the beginning stage of fermentation, laccase activity on stalk of straw, and cottonseed hull was $15.99 \pm 1.30$ and $12.35 \pm 0.60 \mathrm{U} / \mathrm{L}$, and laccase activity was undetected on $P$. beijingensis and corncob. Overall, the presence of stalk of straw was helpful for strain CCMSSC 00118 to accelerate laccase secretion and increase laccase activity. Thus, comparing with other three agro- and forestry residues, stalk of straw was suitable for strain CCMSSC 00118 secreting laccase. On the $1^{\text {st }}$ day, laccase activity for $F$. velutipes strain CCMSSC 05317 was $1.79 \pm 0.11 \mathrm{U} / \mathrm{L}$ on stalk of straw and $2.65 \pm 0.11 \mathrm{U} / \mathrm{L}$ on cottonseed hull. No laccase activity was detected on $P$. beijingensis and corncob (Figs. 1, 2, 3 and 4, respectively). Maximum laccase activity for strain CCMSSC 05317 was $233.21 \pm 1.13 \mathrm{U} / \mathrm{L}$ on stalk of straw, $35.62 \pm 1.62 \mathrm{U} / \mathrm{L}$ on $P$. beijingensis, $47.53 \pm 1.23 \mathrm{U} / \mathrm{L}$ on corncob, and $57.78 \pm 1.30 \mathrm{U} / \mathrm{L}$ on cottonseed hull (Table 2), respectively. Furthermore, on the $10^{\text {th }}$ day, laccase activity for strain CCMSSC 05317 on stalk of straw, P. beijingensis, corncob, and cottonseed hull was $28.21 \pm 0.60$, $1.36 \pm 0.11,5.43 \pm 0.43$, and $11.42 \pm 0.11 \mathrm{U} / \mathrm{L}$, respectively. Clearly, stalk of straw was extremely helpful for strain CCMSSC 05317 to secrete laccase during whole process of solid-state fermentation.

Previous studies concerning lignocellulosic materials using in laccase production secreted by $F$. velutipes were mainly ramie stalk, corncob, and poplar wood (Xie et al. 2017; An et al. 2020b). Han et al. (2017) reported that laccase production from P. ostreatus CCEF 89 and CCEF 99 in synthetic medium containing cottonseed hull was higher than that in poplar wood or corncob with the same synthetic medium.

In the present study, a similar phenomenon was found, because the occurrence time of maximum laccase activity on cottonseed hull was earlier that than on stalk of straw, $P$. beijingensis, and corncob. Maximum laccase activity from $F$. velutipes CCMSSC 05317 in submerged fermentation with cottonseed hull was higher than that with corncob and poplar wood (An et al. 2020b). Meanwhile, maximum laccase activities obtained from $F$. velutipes CCMSSC 00118 grown on cottonseed hull, corncob, and poplar wood were 71.83 $\pm 0.35,58.27 \pm 1.14$, and $42.50 \pm 0.80 \mathrm{U} / \mathrm{L}$ (An et al. 2020b). The presence of cottonseed hull was certainly helpful to improve laccase activity for $P$. ostreatus strains in this study, while, the presence of stalk of straw was more helpful to improve laccase activity for $F$. velutipes strains than cottonseed hull. Additionally, this result confirmed that it was important to select the suitable agro- and forestry residues for different fungi to produce laccase via fermentation. 
Table 2. Maximum Laccase Activity, Agro- and Forestry Residues, and Occurrence Time of Tested Pleurotus ostreatus and Flammulina velutipes Strains

\begin{tabular}{|c|c|c|c|}
\hline $\begin{array}{l}\text { Maximum Laccase } \\
\text { Activity }(\mathrm{U} / \mathrm{L})\end{array}$ & $\begin{array}{c}\text { Agro- and Forestry } \\
\text { Residues }\end{array}$ & Tested Strains & Time (Day) \\
\hline $312.04 \pm 5.52$ & Stalk of straw & $\begin{array}{c}\text { P. ostreatus CCMSSC } \\
00322\end{array}$ & $7^{\text {th }}$ \\
\hline $303.52 \pm 5.41$ & Populus beijingensis & $\begin{array}{c}\text { P. ostreatus CCMSSC } \\
00322\end{array}$ & $7^{\text {th }}$ \\
\hline $321.98 \pm 6.55$ & Corncob & $\begin{array}{c}\text { P. ostreatus CCMSSC } \\
00322\end{array}$ & $7^{\text {th }}$ \\
\hline $594.58 \pm 4.15$ & Cottonseed hull & $\begin{array}{c}\text { P. ostreatus CCMSSC } \\
00322\end{array}$ & $6^{\text {th }}$ \\
\hline $253.95 \pm 5.86$ & Stalk of straw & $\begin{array}{c}\text { P. ostreatus CCMSSC } \\
00406\end{array}$ & $8^{\text {th }}$ \\
\hline $265.86 \pm 13.28$ & Populus beijingensis & $\begin{array}{c}\text { P. ostreatus CCMSSC } \\
00406\end{array}$ & $7^{\text {th }}$ \\
\hline $148.15 \pm 7.38$ & Corncob & $\begin{array}{c}\text { P. ostreatus CCMSSC } \\
00406\end{array}$ & $6^{\text {th }}$ \\
\hline $417.72 \pm 17.99$ & Cottonseed hull & $\begin{array}{c}\text { P. ostreatus CCMSSC } \\
00406\end{array}$ & $5^{\text {th }}$ \\
\hline $271.54 \pm 10.58$ & Stalk of straw & $\begin{array}{c}\text { P. ostreatus CCMSSC } \\
00336\end{array}$ & $7^{\text {th }}$ \\
\hline $174.51 \pm 4.18$ & Populus beijingensis & $\begin{array}{c}\text { P. ostreatus CCMSSC } \\
00336\end{array}$ & $7^{\text {th }}$ \\
\hline $145.00 \pm 2.59$ & Corncob & $\begin{array}{c}\text { P. ostreatus CCMSSC } \\
00336\end{array}$ & $6^{\text {th }}$ \\
\hline $409.44 \pm 6.49$ & Cottonseed hull & $\begin{array}{c}\text { P. ostreatus CCMSSC } \\
00336\end{array}$ & $6^{\text {th }}$ \\
\hline $280.80 \pm 2.75$ & Stalk of straw & $\begin{array}{c}\text { F. velutipes CCMSSC } \\
00114\end{array}$ & $7^{\text {th }}$ \\
\hline $40.62 \pm 0.95$ & Populus beijingensis & $\begin{array}{c}\text { F. velutipes CCMSSC } \\
00114\end{array}$ & $6^{\text {th }}$ \\
\hline $61.67 \pm 2.49$ & Corncob & $\begin{array}{c}\text { F. velutipes CCMSSC } \\
00114\end{array}$ & $7^{\text {th }}$ \\
\hline $59.88 \pm 1.95$ & Cottonseed hull & $\begin{array}{c}\text { F. velutipes CCMSSC } \\
00114\end{array}$ & $6^{\text {th }}$ \\
\hline $239.26 \pm 17.89$ & Stalk of straw & $\begin{array}{c}\text { F. velutipes CCMSSC } \\
00118 \\
\end{array}$ & $6^{\text {th }}$ \\
\hline $32.47 \pm 1.12$ & Populus beijingensis & $\begin{array}{c}\text { F. velutipes CCMSSC } \\
00118\end{array}$ & $7^{\text {th }}$ \\
\hline $36.60 \pm 0.70$ & Corncob & $\begin{array}{c}\text { F. velutipes CCMSSC } \\
00118\end{array}$ & $7^{\text {th }}$ \\
\hline $60.19 \pm 2.80$ & Cottonseed hull & $\begin{array}{c}\text { F. velutipes CCMSSC } \\
00118\end{array}$ & $6^{\text {th }}$ \\
\hline $233.21 \pm 1.13$ & Stalk of straw & $\begin{array}{c}\text { F. velutipes CCMSSC } \\
05317\end{array}$ & $8^{\text {th }}$ \\
\hline $35.62 \pm 1.62$ & Populus beijingensis & $\begin{array}{c}\text { F. velutipes CCMSSC } \\
05317 \\
\end{array}$ & $7^{\text {th }}$ \\
\hline $47.53 \pm 1.23$ & Corncob & $\begin{array}{c}\text { F. velutipes CCMSSC } \\
05317\end{array}$ & $6^{\text {th }}$ \\
\hline $57.78 \pm 1.30$ & Cottonseed hull & $\begin{array}{c}\text { F. velutipes CCMSSC } \\
05317\end{array}$ & $5^{\text {th }}$ \\
\hline
\end{tabular}




\section{Laccase Activity from Different Pleurotus ostreatus and Flammulina velutipes Strains}

Pleurotus ostreatus and Flammulina velutipes have the capacity of secreting laccase (An et al. 2016a, 2018). Previous studies indicated that metal ions have ability of inducing laccase secreted by fungi. Among different metal ions, the presence of $\mathrm{Cu}^{2+}$ or $\mathrm{Mn}^{2+}$ contributed to improving laccase production from $F$. velutipes and $P$. ostreatus strains, and $\mathrm{Fe}^{2+}$ was disadvantageous for $F$. velutipes and $P$. ostreatus strains secreting laccase (Janusz et al. 2015; An et al. 2016a, 2020a). The effects of lignocellulosic materials, such as cottonseed hull and poplar wood, on the activity of laccase in $P$. ostreatus and $F$. velutipes strains via submerged fermentation were also studied (Elisashvili et al. 2008; An et al. 2015, 2020b; Han et al. 2017, 2018, 2020). However, enlarging the screening range of strains and suitable agro- and forestry residues is helpful for obtaining high-produced laccase strains used in industrial application. Thus, in present study, the capacity of secreting laccase from three $P$. ostreatus strains and three $F$. velutipes strains on agro- and forestry residues was considered.

In terms of Populus beijingensis, laccase activity from three P. ostreatus strains was detected on the $1^{\text {st }}$ day, while no laccase activity was detected from three $F$. velutipes strains (Fig. 1). Maximum laccase activity for P. ostreatus CCMSSC 00322 was $303.52 \pm$ 5.41 U/L, nearly 1.14-fold, 1.74-fold, 7.47-fold, 9.35-fold, and 8.52-fold than that for $P$. ostreatus CCMSSC 00406, $P$. ostreatus CCMSSC 00336, F. velutipes CCMSSC 00114, $F$. velutipes CCMSSC 00118, and $F$. velutipes CCMSSC 05317, respectively (Table 2). Clearly, $P$. ostreatus CCMSSC 00322 was the best producer with the capacity of secreting laccase on $P$. beijingensis. The level of secreting laccase from three $F$. velutipes strains was roughly equivalent and was lower than that from three $P$. ostreatus strains (Fig. 1). Laccase activity obtained from $P$. ostreatus CCMSSC 00322, $P$. ostreatus CCMSSC 00406, and $F$. velutipes CCMSSC 00114 on corncob was measured on the $1^{\text {st }}$ day, while the other three strains were not measured this day. Similarly, to the phenomenon on the Populus beijingensis, maximum laccase activity for $P$. ostreatus CCMSSC 00322 was $321.98 \pm$ 6.55 U/L, which was nearly 2.17-fold, 2.22-fold, 5.22-fold, 8.80-fold, and 6.77-fold higher than that for $P$. ostreatus CCMSSC 00406, P. ostreatus CCMSSC 00336, F. velutipes CCMSSC 00114, F. velutipes CCMSSC 00118, and $F$. velutipes CCMSSC 05317, respectively (Table 2). Thus, $P$. ostreatus CCMSSC 00322 was the best producer with the capacity of secreting laccase on corncob and other two $P$. ostreatus strains had similar laccase secretion capacity (Fig. 2). Maximum laccase activity from $F$. velutipes CCMSSC 00114 on corncob was $61.67 \pm 2.49 \mathrm{U} / \mathrm{L}$, nearly 1.68 -fold and 1.30 -fold higher than that from $F$. velutipes CCMSSC 00118 and $F$. velutipes CCMSSC 05317. Maximum laccase activity from these $F$. velutipes strains indicated that the specificity of enzyme production in different strains belonging to the same species was significant. Furthermore, it was also demonstrated once again that the enzyme production capacity of $P$. ostreatus CCMSSC 00322 was much stronger than that of other strains, and each strain had a certain specificity of its own enzyme production through the laccase activity of the six strains grown on corncob on the $10^{\text {th }}$ day. In terms of stalk of straw, laccase activity was detected in these six strains on the $1^{\text {st }}$ day (Fig. 3). Maximum laccase activity from P. ostreatus CCMSSC 00322, CCMSSC 00406, CCMSSC 00336, F. velutipes CCMSSC 00114, CCMSSC 00118, and CCMSSC 05317 on stalk of straw was $312.04 \pm 5.52,253.95 \pm 5.86,271.54 \pm 10.58$, $280.80 \pm 2.75,239.26 \pm 17.89$, and 233.21 $\pm 1.13 \mathrm{U} / \mathrm{L}$ (Table 2), respectively. Among the tested six strains, $P$. ostreatus CCMSSC 00322 was still the best producer in secreting laccase on stalk of straw. Meanwhile, three $F$. velutipes strains exhibited superior capacity 
of secreting laccase due to the high level of laccase activity, especially $F$. velutipes CCMSSC 00114 (Fig. 3). This is the first report about the laccase activity secreted by $P$. ostreatus and $F$. velutipes strains grown on stalk of straw. The report found that stalk of straw was more suitable for $F$. velutipes strains to secrete laccase. Maximum laccase activity from $P$. ostreatus CCMSSC 00322 on cottonseed hull was $594.58 \pm 4.15 \mathrm{U} / \mathrm{L}$, which was nearly 1.42-fold, 1.45-fold, 9.93-fold, 9.88-fold, and 10.29-fold than that for $P$. ostreatus CCMSSC 00406, P. ostreatus CCMSSC 00336, F. velutipes CCMSSC 00114, $F$. velutipes CCMSSC 00118, and $F$. velutipes CCMSSC 05317.

Previous studies indicated that species or different strains belonging to the same species have their own unique characteristics of enzyme production (Janusz et al. 2015; Huang et al. 2019; An et al. 2020a,b; Han et al. 2020). The value of laccase activity from four $P$. ostreatus strains 2175, IBB8, IBB108, and 2191, on tree leaves was no different by solid-state fermentation (Elisashvili et al. 2008). Additionally, the present study indicated that there were differences and showed differentiated specificity in the capacity of secreting laccase from different $P$. ostreatus and $F$. velutipes strains on various agro- and forestry residues. An et al. (2020b) reported that the capacity of secreting laccase from $P$. ostreatus strains was superior to that from $F$. velutipes strains. In this study, similar phenomenon appeared most times, except fermentation on stalk of straw. In terms of overall laccase production capacity, $P$. ostreatus was indeed better than $F$. velutipes due to the value of maximum laccase activity and duration of enzyme production.

\section{CONCLUSIONS}

1. The capacity of secreting laccase was varied from different species or strains belonging to the same species on solid-state fermentation with various agro- and forestry residues.

2. Overall, the capacity of secreting laccase for $P$. ostreatus strains was superior to $F$. velutipes strains due to the value of maximum activity on various agro- and forestry residues, except on stalk of straw.

3. Comparing with Populus beijingensis, corncob and stalk of straw, the presence of cottonseed hull was certainly helpful to improve laccase activity for $P$. ostreatus strains in this study, while, the presence of stalk of straw was more helpful to improve laccase activity for $F$. velutipes strains.

\section{ACKNOWLEDGMENTS}

This research was supported by the National Natural Science Foundation of China (31900009), the Top-notch Youth Project of Colleges and Universities in Hebei Province (BJ2019007), the Fundamental Research Funds for the Universities in Hebei Province (JYQ201901), and the Top-notch Youth Project of Langfang City, China. 


\section{REFERENCES CITED}

Agrawal, K., Chaturvedi, V., and Verma, P. (2018). "Fungal laccase discovered but yet undiscovered," Bioresources and Bioprocessing 5, article no. 4. DOI:

$10.1186 / \mathrm{s} 40643-018-0190-\mathrm{z}$

Agrawal, K., and Verma, P. (2020). "Production optimization of yellow laccase from Stropharia sp. ITCC 8422 and enzyme-mediated depolymerization and hydrolysis of lignocellulosic biomass for biorefinery application," Biomass Conversion and Biorefinery (Early Access). DOI: 10.1007/s13399-020-00869-w

An, Q., Han, M. L., Bian, L. S., Han, Z. C., Han, N., Xiao, Y. F., and Zhang, F. B. (2020a). "Enhanced laccase activity of white rot fungi induced by different metal ions under submerged fermentation," BioResources 15(4), 8369-8383. DOI: 10.15376/biores. 15.4.8369-8383

An, Q., Han, M. L., Wu, X. J., Si, J., Cui, B. K., Dai, Y. C., and Wu, B. (2016a). "Laccase production among medicinal mushrooms from the Genus Flammulina (Agaricomycetes) under different treatments in submerged fermentation," International Journal of Medicinal Mushrooms 18(11), 1049-1059. DOI: 10.1615/IntJMedMushrooms.v18.i11.90

An, Q., Ma, H. F., Han, M. L., Si, J., and Dai, Y. C. (2018). "Effects of different induction media as inducers on laccase activities of Pleurotus ostreatus strains in submerged fermentation," BioResources 13(1), 1143-1156. DOI: 10.15376/biores.13.1.1143-1156

An, Q., Qiao, J., Bian, L. S., Han, M. L., Yan, X. Y., Liu, Z. Z., and Xie, C. Y. (2020b). "Comparative study on laccase activity of white rot fungi under submerged fermentation with different lignocellulosic wastes," BioResources 15(4), 9166-9179. DOI: 10.15376/biores. 15.4.9166-9179

An, Q., Wu, X. J., Han, M. L., Cui, B. K., He, S. H., Dai, Y. C., and Si, J. (2016b). "Sequential solid-state and submerged cultivation of white rot fungus Pleurotus ostreatus on lignocellulosic biomass for the activity of lignocellulolytic enzymes," BioResources 11(4), 8791-8805. DOI: 10.15376/biores.11.4.8791-8805

An, Q., Wu, X. J., Wu, B., and Dai, Y. C. (2015). "Effects of carbon and nitrogen sources on lignocellulose decomposition enzyme activities in Flammulina velutipes," Mycosystema 34(4), 761-771. DOI: 10.13346/j.mycosystema.150060

Atilano-Camino, M. M., Alvarez-Valencia, L. H., Garcia-Gonzalez, A., and GarciaReyes, R. B. (2020). "Improving laccase production from Trametes versicolor using lignocellulosic residues as cosubstrates and evaluation of enzymes for blue wastewater biodegradation," Journal of Environmental Management 275, article no. 111231. DOI: 10.1016/j.jenvman.2020.111231

Bertrand, B., Martinez-Morales, F., and Trejo-Hernandez, M. R. (2017). "Upgrading laccase production and biochemical properties: Strategies and challenges," Biotechnology Progress 33(4), 1015-1034. DOI: 10.1002/btpr.2482

Couto, S. R., and Toca-Herrera, J. L. (2007). "Laccase production at reactor scale by filamentous fungi," Biotechnology Advances 25(6), 558-569. DOI: 10.1016/j.biotechadv.2007.07.002

Deska, M., and Konczak, B. (2019). "Immobilized fungal laccase as "green catalyst" for the decolourization process - state of the art," Process Biochemistry 84, 112-123.

DOI: 10.1016/j.procbio.2019.05.024

Diaz, R., Tellez-Tellez, M., Sanchez, C., Bibbins-Martinez, M. D., Diaz-Godinez, G., and 
Soriano-Santos, J. (2013). "Influence of initial pH of the growing medium on the activity, production and genes expression profiles of laccase of Pleurotus ostreatus in submerged fermentations," Electronic Journal of Biotechnology 16(4), article no. 6. DOI: 10.2225/vol16-issue4-fulltext-6

Divya, L. M., Prasanth, G. K., and Sadasivan, C. (2015). "Assessing the tolerance of immobilized laccase from a salt-tolerant strain of Trichoderma viride Pers NFCCI2745 to heavy metal ions, detergents and copper chelating agents," International Journal of Environmental Science and Technology 12(10), 3225-3234. DOI: 10.1007/s13762-014-0697-6

Elisashvili, V., and Kachlishvili, E. (2009). "Physiological regulation of laccase and manganese peroxidase production by white-rot Basidiomycetes," Journal of Biotechnology 144(1), 37-42. DOI: 10.1016/j.jbiotec.2009.06.020

Elisashvili, V., Penninckx, M., Kachlishvili, E., Tsiklauri, N., Metreveli, E., Kharziani, T., and Kvesitadze, G. (2008). "Lentinus edodes and Pleurotus species lignocellulolytic enzymes activity in submerged and solid-state fermentation of lignocellulosic wastes of different composition," Bioresource Technology 99(3), 457462. DOI: 10.1016/j.biortech.2007.01.011

Elissetche, J., Ferraz, A., Freer, J., and Rodríguez, J. (2007). "Enzymes produced by Ganoderma australe growing on wood and in submerged cultures," World Journal of Microbiology and Biotechnology 23, 429. DOI: 10.1007/s11274-006-9243-0

Gaikwad, A., and Meshram, A. (2019). "Effect of particle size and mixing on the laccasemediated pretreatment of lignocellulosic biomass for enhanced saccharification of cellulose," Chemical Engineering Communications 207(12), 1696-1706. DOI: 10.1080/00986445.2019.1680364

Galhaup, C., Wagner, H., Hinterstoisser, B., and Haltrich, D. (2002). "Increased production of laccase by the wood-degrading basidiomycete Trametes pubescens," Enzyme and Microbial Technology 30(4), 529-536. DOI: 10.1016/S01410229(01)00522-1

Garlapati, D., Chandrasekaran, M., Devanesan, A., Mathimani, T., and Pugazhendhi, A. (2019). "Role of cyanobacteria in agricultural and industrial sectors: An outlook on economically important byproducts," Applied Microbiology and Biotechnology 103(12), 4709-4721. DOI: 10.1007/s00253-019-09811-1

Guo, C. L., Zhao, L. T., Wang, F., Lu, J., Ding, Z. Y., and Shi, G. Y. (2017). “Betacarotene from yeasts enhances laccase production of Pleurotus eryngii var. ferulae in co-culture," Frontiers in Microbiology 8, article no. 1101. DOI: 10.3389/fmicb.2017.01101

Gupta, A., and Jana, A. K. (2018). "Effects of wheat straw solid contents in fermentation media on utilization of soluble/insoluble nutrient, fungal growth and laccase production," 3 Biotech 8, article no. 35. DOI: 10.1007/s13205-017-1054-5

Gupta, A., and Jana, A. K. (2019). "Production of laccase by repeated batch semi-solid fermentation using wheat straw as substrate and support for fungal growth," Bioprocess and Biosystems Engineering 42(3), 499-512. DOI: 10.1007/s00449-0182053-6

Han, M. L., An, Q., He, S. F., Zhang, X. L., Zhang, M. H., Gao, X. H., Wu, Q., and Bian, L. S. (2020). "Solid-state fermentation on poplar sawdust and corncob wastes for lignocellulolytic enzymes by different Pleurotus ostreatus strains," BioResources 15(3), 4982-4995. DOI: 10.15376/biores.15.3.4982-4995

Han, M. L., An, Q., Wu, X. J., Zheng, F., and Si, J. (2017). "Effects of different 
lignocellulose as inducers on laccase activities of Pleurotus ostreatus in submerged fermentation," Mycosystema 36(3), 349-357. DOI: 10.13346/j.mycosystema.160055

Han, M. L., Du, J., An, Q., and Li, C. S. (2018). "Effects of different culture substrate on laccase activities of Pleurotus ostreatus under different fermentation conditions," Mycosystema 37(8), 1100-1108. DOI: 10.13346/j.mycosystema.180064

Han, M. L., Yang, J., Liu, Z. Y., Wang, C. R., Chen, S. Y., Han, N., Hao, W. Y., An, Q., and Dai, Y. C. (2021). "Evaluation of laccase activities by three newly isolated fungal species in submerged fermentation with single or mixed lignocellulosic wastes," Frontiers in Microbiology 12, article no. 682679. DOI: 10.3389/fmicb.2021.682679

Huang, L., Sun, N., Ban, L., Wang, Y., and Yang, H. P. (2019). "Ability of different edible fungi to degrade crop straw," AMB Express 9, article no. 4. DOI: $10.1186 / \mathrm{s} 13568-018-0731-\mathrm{Z}$

Hu, X., Wang, C. Y., Wang, L., Zhang, R. R., and Chen, H. (2014). "Influence of temperature, $\mathrm{pH}$ and metal ions on guaiacol oxidation of purified laccase from Leptographium qinlingensis," World Journal of Microbiology and Biotechnology 30(4), 1285-1290. DOI: 10.1007/s11274-013-1554-3

Janusz, G., Czuryło, A., Frąc, M., Rola, B., Sulej, J., Pawlik, A., Siwulski, M., and Rogalski, J. (2015). "Laccase production and metabolic diversity among Flammulina velutipes strains," World Journal of Microbiology and Biotechnology 31(1), 121-133. DOI: 10.1007/s11274-014-1769-y

Jaya Mary, J., Karthik, C., Smita, G. R., Kumar, S., Prabakar, D., Kadirvelu, K., and Pugazhendhi, A. (2018). "Biological approaches to tackle heavy metal pollution: A survey of literature," Journal of Environmental Management 217, 56-70. DOI: 10.1016/j.jenvman.2018.03.077

Kudanga, T., Nemadziva, B., and Le Roes-Hill, M. (2017). "Laccase catalysis for the synthesis of bioactive compounds," Applied Microbiology and Biotechnology 101(1), 13-33. DOI: $10.1007 / \mathrm{s} 00253-016-7987-5$

Lamia, M. H., Farid, Z., Sonia, M. A., Sevastianos, R., Samia, A., Véronique, D., and Mouloud, K. (2017). "Selective isolation and screening of actinobacteria strains producing lignocellulolytic enzymes using olive pomace as substrate," Iranian Journal of Biotechnology 15(1), 74-77. DOI: 10.15171/ijb.1278

Leite, P., Silva, C., Salgado J. M., and Belo, I. (2019). "Simultaneous production of lignocellulolytic enzymes and extraction of antioxidant compounds by solid-state fermentation of agro-industrial wastes," Industrial Crops and Products 137, 315-322. DOI: 10.1016/j.indcrop.2019.04.044

Lizardi-Jimenez, M. A., Ricardo-Diaz, J., Quinones-Munoz, T. A., Hernandez-Rosas, F., and Hernandez-Martinez, R. (2019). "Fungal strain selection for protease production by solid-state fermentation using agro-industrial waste as substrates," Chemical Papers 73(10), 2603-2610. DOI: 10.1007/s11696-019-00814-w

Liu, Y., Luo, G., Ngo, H. H., Guo, W. S., and Zhang, S. C. (2020). “Advances in thermostable laccase and its current application in lignin-first biorefinery: A review," Bioresource Technology 298, article no. 122511. DOI: 10.1016/j.biortech.2019.122511

Mate, D. M., and Alcalde, M. (2017). "Laccase: A multi-purpose biocatalyst at the forefront of biotechnology," Microbial Biotechnology 10(6), 1457-1467. DOI: 10.1111/1751-7915.12422

Oostra, J., Tramper, J., and Rinzema, A. (2000). "Model-based bioreactor selection for large-scale solid-state cultivation of Coniothyrium minitans spores on oats," Enzyme 
and Microbial Technology 27(9), 652-663. DOI: 10.1016/S0141-0229(00)00261-1

Palazzolo, M. A., Postemsky, P. D., and Kurina-Sanz, M. (2019). "From agro-waste to tool: Biotechnological characterization and application of Ganoderma lucidum E47 laccase in dye decolorization," 3 Biotech 9(6), article no. 213. DOI: 10.1007/s13205019-1744-2

Pezzella, C., Lettera, V., Piscitelli, A., Giardina, P., and Sannia, G. (2013). "Transcriptional analysis of Pleurotus ostreatus laccase genes," Applied Microbiology and Biotechnology 97(2), 705-717. DOI: 10.1007/s00253-012-3980-9

Pinar, O., Karaosmanoğlu, K., Sayar, N. A., Kula, C., Kazan, D., and Sayar, A. A. (2017). "Assessment of hazelnut husk as a lignocellulosic feedstock for the production of fermentable sugars and lignocellulolytic enzymes," 3 Biotech 7, article no. 367. DOI: $10.1007 / \mathrm{s} 13205-017-1002-4$

Pinheiro, V. E., Michelin, M., Vici, A. C., de Almeida, P. Z., and Polizeli, M. D. T. D. (2020). "Trametes versicolor laccase production using agricultural wastes: A comparative study in Erlenmeyer flasks, bioreactor and tray," Bioprocess and Biosystems Engineering 43(3), 507-514. DOI: 10.1007/s00449-019-02245-z

Rajavat, A. S., Rai, S., Pandiyan, K., Kushwaha, P., Choudhary, P., Kumar, M., Chakdar, H., Singh, A., Karthikeyan, N., Bagul, S. Y., et al. (2020). "Sustainable use of the spent mushroom substrate of Pleurotus florida for production of lignocellulolytic enzymes," Journal of Basic Microbiology 60(2), 173-184. DOI:

10.1002/jobm.201900382

Rodrigues, E. M., Karp, S. G., Malucelli, L. C., Helm, C. V., and Alvarez, T. M. (2019). "Evaluation of laccase production by Ganoderma lucidum in submerged and solidstate fermentation using different inducers," Journal of Basic Microbiology 59(8), 784-791. DOI: 10.1002/jobm.201900084

Sadeghian-Abadi, S., Rezaei, S., Yousefi-Mokri, M., and Faramarzi, M. A. (2019). "Enhanced production, one-step affinity purification, and characterization of laccase from solid-state culture of Lentinus tigrinus and delignification of pistachio shell by free and immobilized enzyme," Journal of Environmental Management 244, 235-246. DOI: 10.1016/j.jenvman.2019.05.058

Schalchli, H., Hormazabal, E., Rubilar, O., Briceno, G., Mutis, A., Zocolo, G. J., and Diez, M. C. (2017). "Production of ligninolytic enzymes and some diffusible antifungal compounds by white-rot fungi using potato solid wastes as the sole nutrient source," Journal of Applied Microbiology 123(4), 886-895. DOI: 10.1111/jam.13542

Singh, G., and Arya, S. K. (2019). "Utility of laccase in pulp and paper industry: A progressive step towards the green technology," International Journal of Biological Macromolecules 134, 1070-1084. DOI: 10.1016/j.ijbiomac.2019.05.168

Sharma, N., Kalra, K. L., Oberoi, H. S., and Bansal, S. (2007). "Optimization of fermentation parameters for production of ethanol from kinnow waste and banana peels by simultaneous saccharification and fermentation," Indian Journal of Microbiology 47, 310-316. DOI: 10.1007/s12088-007-0057-z

Songulashvili, G. G., Elisashvili, V., Wasser, S. P., Hadar, Y., and Nevo, E. (2008). "Effect of the carbon source and inoculum preparation method on laccase and manganese peroxidase production in submerged cultivation by the medicinal mushroom Ganoderma lucidum (W. Curt.: Fr.) P. Karst. (Aphyllophoromycetideae)," International Journal of Medicinal Mushrooms 10(1), 79-86. DOI:

10.1615/IntJMedMushr.v10.i1.100

Srinivasan, P., Selvankumar, T., Kamala-Kannan, S., Mythili, R., Sengottaiyan, A., 
Govarthanan, M., Senthilkumar, B., and Selvam, K. (2019). "Production and purification of laccase by Bacillus sp. using millet husks and its pesticide degradation application," 3 Biotech 9(11), article no. 396. DOI: 10.1007/s13205-019-1900-8

Suetomi, T., Sakamoto, T., Tokunaga, Y., Kameyama, T., Honda, Y., Kamitsuji, H., Kameshita, I., Izumitsu, K., Suzuki, K., and Irie, T. (2015). "Effects of calmodulin on expression of lignin-modifying enzymes in Pleurotus ostreatus," Current Genetics 61(2), 127-140. DOI: 10.1007/s00294-014-0460-z

Su, J., Fu, J. J., Wang, Q., Silva, C., and Cavaco-Paulo, A. (2018). "Laccase: A green catalyst for the biosynthesis of poly-phenols," Critical Reviews in Biotechnology 38(2), 294-307. DOI: 10.1080/07388551.2017.1354353

Thamvithayakorn, P., Phosri, C., Pisutpaisal, N., Krajangsang, S., Whalley, A. J. S., and Suwannasai, N. (2019). "Utilization of oil palm decanter cake for valuable laccase and manganese peroxidase enzyme production from a novel white-rot fungus, Pseudolagarobasidium sp. PP17-33," 3 Biotech 9(11), article no. 417. DOI: 10.1007/s13205-019-1945-8

Vrsanska, M., Voberkova, S., Langer, V., Palovcikova, D., Moulick, A., Adam, V., and Kopel, P. (2016). "Induction of laccase, lignin peroxidase and manganese peroxidase activities in white-rot fungi using copper complexes," Molecules 21(11), article no. 1553. DOI: $10.3390 /$ molecules 21111553

Wang, F., Xu, L., Zhao, L. T., Ding, Z. Y., Ma, H. L., and Terry, N. (2019). "Fungal laccase production from lignocellulosic agricultural wastes by solid-state fermentation: A review," Microorganisms 7(12), article no. 665. DOI: 10.3390/microorganisms7120665

Wang, X. W., Hu, J., Liang, Y., and Zhan, H. Y. (2011). "Effects of metal ions on laccase activity," Asian Journal of Chemistry 23(12), 5422-5424.

Wasak, A., Drozd, R., Grygorcewicz, B., Jankowiak, D., and Rakoczy, R. (2018). "Purification and recovery of laccase produced by submerged cultures of Trametes versicolor by three-phase partitioning as a simple and highly efficient technique," Polish Journal of Chemical Technology 20(4), 88-95. DOI: 10.2478/pjct-2018-0059

Xie, C. L., Gong, W. B., Yan, L., Zhu, Z. H., Hu, Z. X., and Peng, Y. D. (2017). "Biodegradation of ramie stalk by Flammulina velutipes: Mushroom production and substrate utilization," AMB Express 7, article no. 171. DOI: 10.1186/s13568-0170480-4

Xu, S., Wang, F., Fu, Y. P., Li, D., Sun, X. Z., Li, C. T., Song, B., and Li, Y. (2020). "Effects of mixed agro-residues (corn crop waste) on lignin-degrading enzyme activities, growth, and quality of Lentinula edodes," RSC Advances 10(17), 97989807. DOI: 10.1039/c9ra10405d

Xu, X. Q., Huang, X. H., Liu, D., Lin, J., Ye, X. Y., and Yang, J. (2018). "Inhibition of metal ions on Cerrena sp. laccase: Kinetic, decolorization and fluorescence studies," Journal of the Taiwan Institute of Chemical Engineers 84, 1-10. DOI: 10.1016/j.jtice.2017.12.028

Yang, J., Li, W. J., Ng, T. B., Deng, X. Z., Lin, J., and Ye, X. Y. (2017). “Laccases: Production, expression regulation, and applications in pharmaceutical biodegradation," Frontiers in Microbiology 8, article no. 832. DOI: 10.3389/fmicb.2017.00832

Yashas, S. R., Shivakumara, B. P., Udayashankara, T. H., and Krishna, B. M. (2018). "Laccase biosensor: Green technique for quantification of phenols in wastewater (a review)," Oriental Journal of Chemistry 34(2), 631-637. DOI: 10.13005/ojc/340204 
Zerva, A., Simic, S., Topakas, E., and Nikodinovic-Runic, J. (2019). "Applications of microbial laccases: Patent review of the past decade (2009-2019)," Catalysts 9(12), article no. 1023. DOI: 10.3390/catal9121023

Zhang, Q., Zhao, L. T., Li, Y. R., Wang, F., Li, S., Shi, G. Y., and Ding, Z. Y. (2020). "Comparative transcriptomics and transcriptional regulation analysis of enhanced laccase production induced by co-culture of Pleurotus eryngii var. ferulae with Rhodotorula mucilaginosa," Applied Microbiology and Biotechnology 104(1), 241255. DOI: 10.1007/s00253-019-10228-Z

Zhuo, R., Yuan, P., Yang, Y., Zhang, S., Ma, F. Y., and Zhang, X. Y. (2017). "Induction of laccase by metal ions and aromatic compounds in Pleurotus ostreatus HAUCC 162 and decolorization of different synthetic dyes by the extracellular laccase," Biochemical Engineering Journal 117(Part B), 62-72. DOI: 10.1016/j.bej.2016.09.016

Article submitted: February 24, 2021; Peer review completed: April 17, 2021; Revised version received: September 8, 2021; Accepted: September 11, 2021; Published:

September 14, 2021.

DOI: 10.15376/biores.16.4.7337-7354 